\title{
Turning a Substrate Peptide into a Potent Inhibitor for the Histone Methyltransferase SETD8
}

\author{
Russell A. Judge, ${ }^{\ddagger}$ Haizhong Zhu, ${ }^{\ddagger}$ Anup K. Upadhyay, ${ }^{\ddagger}$ Pierre M. Bodelle, ${ }^{\ddagger}$ Charles W. Hutchins, ${ }^{\ddagger}$
} Maricel Torrent, ${ }^{\ddagger}$ Violeta L. Marin, Wenyu Yu, ${ }^{\S}{ }^{\dagger}$ Masoud Vedadi, ${ }^{\S}$ Fengling Li, ${ }^{\S}$ Peter J. Brown, ${ }^{\S}$ William N. Pappano, Chaohong Sun, ${ }^{+}$and Andrew M. Petros $*$,

${ }^{\ddagger}$ AbbVie Inc., 1 North Waukegan Road, North Chicago, Illinois 60064, United States

${ }^{\S}$ Structural Genomics Consortium, University of Toronto, 101 College Street, Toronto, ON M5G 1L7, Canada

\section{Supporting Information}

ABSTRACT: SETD8 is a histone H4-K20 methyltransferase that plays an essential role in the maintenance of genomic integrity during mitosis and in DNA damage repair, making it an intriguing target for cancer research. While some small molecule inhibitors for SETD8 have been reported, the structural binding modes for these inhibitors have not been revealed. Using the complex structure of the substrate peptide bound to SETD8 as a starting point, different natural and unnatural amino acid substitutions were tested, and a potent $\left(K_{\mathrm{i}} 50 \mathrm{nM}, \mathrm{IC}_{50} 0.33 \mu \mathrm{M}\right)$ and selective norleucine containing peptide inhibitor has been obtained.
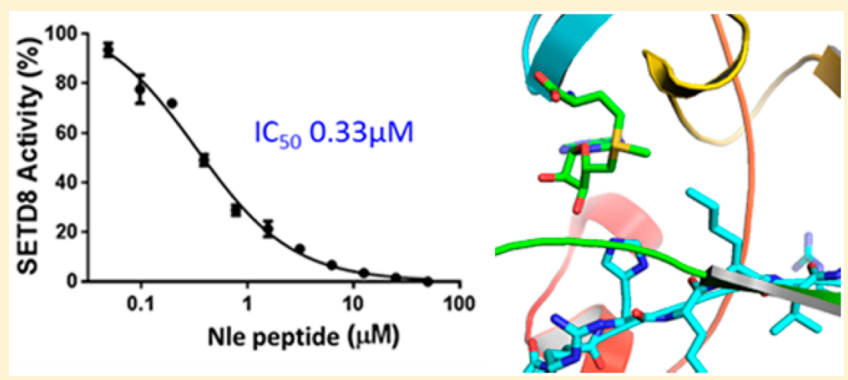

KEYWORDS: SETD8, HMT, drug design, structure-based drug design, cancer

SETD8 (also known as SET8, PR-SET7, and KMT5A) is a histone lysine methyltransferase (HMT). It is the only methyltransferase known to catalyze the monomethylation of histone $\mathrm{H} 4$ at lysine $20{ }^{1}$ This methyl mark has been implicated in regulating a number of key cellular processes including DNA damage repair, DNA replication, mitotic condensation and regulation, and gene regulation. ${ }^{1-3}$ In addition, SETD8 also methylates nonhistone proteins including p53 and the proliferating cell nuclear antigen (PCNA). SETD8 lysine methylation of $\mathrm{p} 53$ regulates this tumor suppressor protein, with depletion of SETD8 augmenting the proapoptotic and checkpoint activation functions of $\mathrm{p} 53$. $^{4}$ For PCNA, aberrant lysine methylation of this protein may play a role in the proliferation of cancer cells. ${ }^{5}$ Further, SETD8 is reported to play a role in breast cancer tumor invasion and metastasis in association with the transcription factor TWIST. ${ }^{6}$ Overexpression of SETD8 has also been observed in a number of cancers, including nonsmall cell lung carcinoma, small cell lung carcinoma, chronic myelogenous leukemia, hepatocellular carcinoma, pancreatic cancer and bladder cancer. ${ }^{5}$ Given the scope of its interactions and potential roles in tumorigenesis, developing inhibitors for SETD8 is therefore of interest for anticancer therapy.

SETD8 is a 352 residue protein, however, full methyltransferase activity is retained by a $\sim 160$ residue C-terminal fragment. ${ }^{7}$ Employing this active, C-terminal fragment, some small molecule inhibitors of SETD8 have been previously reported. Williams et al. $^{8}$ report Nahuoic acid, a natural product isolated from a tropical marine sediment, to be a $S$ - adenosylmethionine (SAM) competitive inhibitor $\left(\mathrm{IC}_{50} 6.5\right.$ $\left.\mu \mathrm{M}, K_{\mathrm{i}} 2 \mu \mathrm{M}\right)$ and selective for SETD8 against a panel of nine HMTs. Blum et al. ${ }^{9}$ used high throughput screening to identify three compounds with different binding characteristics, the best with an $\mathrm{IC}_{50}$ of $0.2 \mu \mathrm{M}$. Valente et al. ${ }^{10}$ identified bis(bromo/ dibromo-methoxyphenol) derivatives, the best showing an $\mathrm{EC}_{50}$ of $2.6 \mu \mathrm{M}$. Ma et al. ${ }^{11}$ reported UNC0379, which is identified as a substrate peptide competitive inhibitor $\left(\mathrm{IC}_{50}\right.$ of $\left.7.3 \mu \mathrm{M}\right)$ and selective for SETD8 over 15 other methyltransferases. In further structure-activity relationship studies utilizing UNC0379 additional substrate peptide competitive compounds were also discovered. ${ }^{12}$ Despite these inhibitor reports, structural details of their binding modes have not been revealed, as the only reported complex structures for SETD8 are with SAM alone ${ }^{13}$ and with $S$-adenosylhomocysteine (SAH) and the $\mathrm{H} 4$ substrate peptide. ${ }^{2}$

While SETD8 inhibitors could, in principle, be designed to target the SAM cofactor binding site as was done for $\mathrm{EZH} 2^{14}$ and DOT $1 \mathrm{~L}^{15}$ or the substrate peptide site as was done for G9a ${ }^{16}$ and SMYD2, ${ }^{17}$ we initially chose to target the peptide site using the $\mathrm{H} 4$ substrate peptide as a starting point for inhibitor design. Inhibitors derived from peptides have been developed for other targets of potential therapeutic importance such as IAPs, ${ }^{18}$ beta secretase, ${ }^{19} 14-3-3$ proteins, ${ }^{20}$ the Bcl family of proteins, ${ }^{21}$ and IL-17A. ${ }^{22}$ With this in mind, and based

Received: August 3, 2016

Accepted: October 11, 2016

Published: October 11, 2016 
on a careful analysis of the structure of the bound substrate peptide, ${ }^{2}$ we have designed a potent peptide-based inhibitor of SETD8, which will be useful not only as an in vitro tool to further study SETD8 function but also can potentially be turned into a potent cell-penetrant inhibitor for in vivo studies of SETD8 inhibition.

The $\mathrm{H} 4$ peptide utilized in these studies (amino acids 16-23 of histone H4) consists of the following residue: KRHRKVLR, with $\mathrm{K} 20$ (underlined) being the target residue for methylation. The experimental design focused on three main areas, the core lysine residue, the $\mathrm{N}$-terminal region, and the $\mathrm{C}$-terminal region as illustrated in Figure 1. For the core replacement, a careful

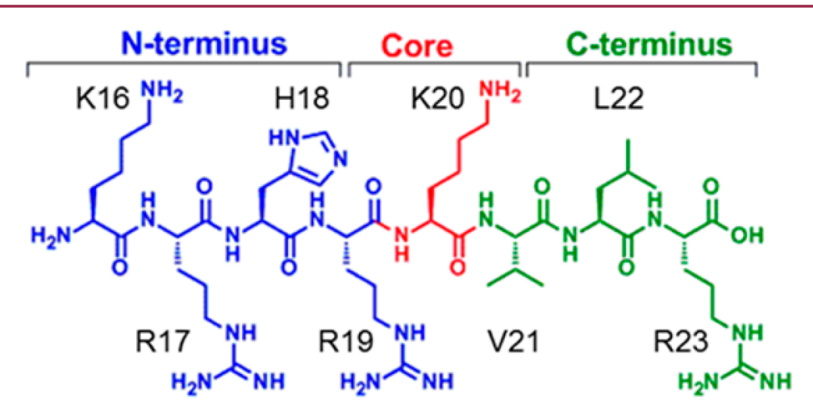

Figure 1. H4 peptide (16-23) areas of focus for design.

examination of the crystal structure of the $\mathrm{H} 4$ peptide (residues 16-24) bound to SETD $8^{2}$ reveals that the subpocket into which $\mathrm{K} 20$ binds provides no counter charge for the very basic $\varepsilon$-amino group of the side chain (Figure 2 ). Note this is the $\varepsilon$ -

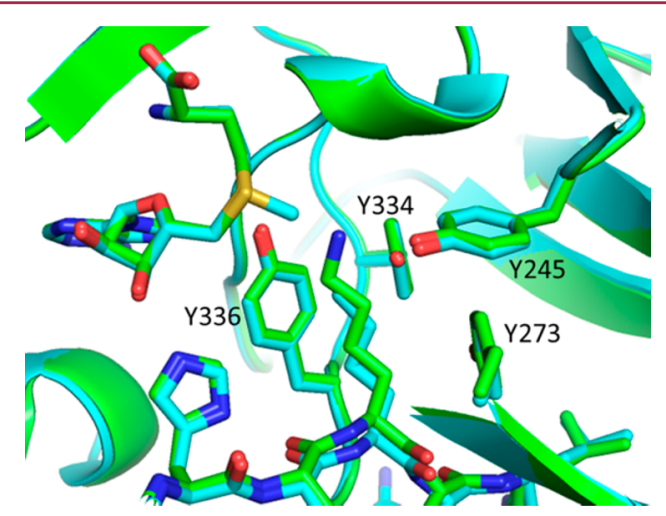

Figure 2. Overlay of the norleucine substituted peptide (2) complex structure (light blue, PDB ID: 5TEG) and the native H4 peptide complex structure (green, PDB ID: $1 \mathrm{ZKK}^{2}$ ). Residues from SETD8 forming the lysine channel are highlighted as sticks against the background of SETD8 shown as a cartoon. SAM/SAH, respectively, is shown as sticks at the top left. Figure prepared using PyMOL. ${ }^{23}$

amino group that gets methylated by the enzyme. There are three phenolic hydroxyl groups nearby (Y245, Y334, and Y336), but only the hydroxyl from Y245 is in proximity with a reasonable angle to make a hydrogen bond to the lysine amino group. Below the amino group the pocket is flanked by Y336 and Y273 and is, overall, quite hydrophobic. Therefore, insertion of K20 would not appear to be energetically favored. Our hypothesis was that replacement of K20 with a residue bearing a more hydrophobic side chain, which could interact in a more energetically favorable manner with the protein side chains of the lysine subpocket, may provide a relatively simple way to turn this substrate peptide into an inhibitor of SETD8 methyltransferase activity.

Toward that end we began with the molecular modeling program Maestro $^{24}$ and utilized the crystal structure of SETD8 in complex with the $\mathrm{H} 4$ peptide and SAH (PDB ID: 1ZKK), ${ }^{2}$ manually substituting the side chain of $\mathrm{K} 20$ in the $\mathrm{H} 4$ peptide with various side chains from both natural and unnatural amino acids. In each case a simple minimization was performed and the steric fit in the binding site visually evaluated. A set of mutant $\mathrm{H} 4$ peptides was then designed and made in which the native (16-23) H4 peptide (1) was mutated at residue 20 with the following substitutions; norleucine (Nle) (2), methionine (3), beta-2-thienylalanine (4), 2-(3-thienyl)-glycine (5), $p$ nitrophenylalanine (6), $p$-chlorophenylalanine (7), and tryptophan (8). All peptides were first screened for binding to SETD 8 by NMR. Those that exhibited some degree of binding by NMR were then evaluated by isothermal titration calorimetry (ITC). As a reference, the binding of the unmodified substrate peptide (1) was also measured (Table 1 ).

Table 1. ITC Binding of the Native H4 and K20 Substituted Mutant Peptides (16-23)

\begin{tabular}{|c|c|c|}
\hline Peptide & Side chain & $\mathbf{K}_{d}(\mu \mathbf{M})$ \\
\hline 1 & & $46.60 \pm 2.80$ \\
\hline 2 & & $0.14 \pm 0.01$ \\
\hline 3 & & $1.26 \pm 0.05$ \\
\hline 4 & & $1.58 \pm 0.10$ \\
\hline 5 & & $6.70 \pm 0.50$ \\
\hline 6 & & - \\
\hline 7 & & - \\
\hline 8 & & - \\
\hline
\end{tabular}

Note, the ITC measurements for peptides 3 to 8 were performed in $20 \mathrm{mM}$ HEPES $\mathrm{pH} 7.0,50 \mathrm{mM} \mathrm{NaCl}, 0.5 \mathrm{mM}$ TCEP buffer. All other measurements were performed in PBS buffer containing $0.5 \mathrm{mM}$ TCEP. This is expected to make marginal difference as the $K_{\mathrm{d}}$ for peptide (2) in the HEPES buffer was $0.24 \mu \mathrm{M}$.

The peptides with substitutions norleucine (2), methionine (3), beta-2-thienylalanine (4), and 2-(3-thienyl)-glycine (5) bound tighter than the native peptide, while peptides with the bulkier substitutions $p$-nitrophenylalanine (6), p-chlorophenylalanine (7), and tryptophan (8) were much weaker and were beyond the detection limit of the assay. Of all the substitutions generated, the peptide with the norleucine replacement (2) 
showed the best binding (ITC curve in Supporting Information, Figure S1). Without the basic charge and with a shorter and more hydrophobic side chain the norleucine residue fits nicely in the lower hydrophobic region of the pocket and provides a more energetically favored interaction. The peptides containing sulfur substitutions (methionine (3), beta-2-thienylalanine (4), and 2-(3-thienyl)-glycine (5)) also bound tighter than the native peptide, likely due to the partial hydrophobic nature of the side chains, but they did not bind as well as the norleucine peptide (2). When these mutant peptides were initially screened for SETD8 binding by NMR it was observed that the spectral perturbations upon binding were very similar to those observed for the substrate peptide, suggesting a substrate conserved binding mode (Supporting Information, Figure S2). In order to more fully understand the binding of the norleucine peptide (2), a crystal structure of SETD8 in complex with this peptide was obtained (Figure 2).

The structure of this ternary complex was solved to $1.3 \AA$ resolution and the refinement statistics are outlined in the Supporting Information, Table S1. The overall conformation of the SETD8 protein is essentially identical to that reported for the ternary complex of SETD8 bound to (SAH) and substrate peptide, ${ }^{2}$ with the norleucine side chain oriented identically to that of the lysine 20 side chain of the substrate peptide. In addition, the norleucine containing peptide (2) does not appear to make any additional interactions with the protein as compared to the substrate peptide thus providing further evidence that the increase in potency for the mutant peptide compared to the substrate peptide is simply the result of replacing the core lysine.

Based on the norleucine containing peptide (2), further peptides were made in which norleucine was maintained at position 20, while the $\mathrm{N}$ and $\mathrm{C}$ termini were truncated (RHR(Nle)VLR (9) and HR(Nle)VL (10)). These peptides were then tested by ITC. The truncations resulted in weaker binding, $K_{\mathrm{d}}=0.35 \pm 0.01$ and $15 \pm 2.0 \mu \mathrm{M}$, respectively. Of the peptide lengths examined, 16-23 shows the best binding.

Having identified the $\mathrm{K} 20$ norleucine mutant and a peptide length of 16-23 as the best modified peptide, the effect of further substitutions for residues in the $\mathrm{N}$ and $\mathrm{C}$-termini were explored. These substitutions were chosen based on molecular modeling in an attempt to further improve affinity. Near the Nterminus, modeling identified $\mathrm{R} 17$ as the most promising residue to modify. R17 sits in a well-defined groove right next to C270 in the SETD8 protein (Supporting Information, Figure S3a). Near the C-terminus, L22 was selected as the most promising point for substitution. L22 pokes into a hydrophobic pocket in the SETD8 protein adjacent to the interface of various beta strands (Supporting Information, Figure S3b). At each of these two positions, a number of natural and unnatural residue substitutions were evaluated utilizing molecular modeling (Maestro ${ }^{24}$ ). Both electrostatics and shape complementarity were taken into account to rank order all possible candidates. Only the top dozen candidates with the best global fit were selected for subsequent synthesis and NMR screening. The following H4 (16-23) norleucine substituted peptides were then selected for binding studies by ITC: peptides KRHR(Nle)VLR with R17 substitution L-homoleucine (11), tert-butyl-L-cysteine (12), isoleucine (13), and methionine (14) and the peptides KRHR(Nle)VLR with L22 substitution betacyclohexylalanine (15), L-homoleucine (16), o-methyl-Ltyrosine (17), tert-butyl-L-cysteine (18), L-3-pyridylanaline (19), $o$-acetyl-L-serine (20), isoleucine (21), and L-methionine sulfone (22). The results for the substitution of R17 are shown in Table 2 and for L22 in Table 3.

Table 2. Effect of Substitutions for R17 in the Peptide KRHR(Nle)VLR

\begin{tabular}{|c|c|c|}
\hline Peptide & Side chain & $\mathbf{K}_{\mathrm{d}}, \boldsymbol{\mu} \mathbf{M}$ \\
\hline 11 & & $1.84 \pm 0.14$ \\
\hline 12 & & $3.04 \pm 0.33$ \\
\hline 13 & & $5.57 \pm 0.36$ \\
\hline 14 & & $14.80 \pm 2.00$ \\
\hline
\end{tabular}

Table 3. Effect of Substitutions for L22 in the Peptide KRHR(Nle)VLR

\begin{tabular}{|c|c|c|}
\hline Peptide & Side chain & $\mathbf{K}_{\mathrm{d}}, \boldsymbol{\mu} \mathbf{M}$ \\
\hline 15 & & $0.12 \pm 0.01$ \\
\hline 16 & & $0.21 \pm 0.01$ \\
\hline 17 & & $0.32 \pm 0.02$ \\
\hline 18 & & $0.58 \pm 0.01$ \\
\hline 19 & & $0.80 \pm 0.04$ \\
\hline 20 & & $4.64 \pm 0.19$ \\
\hline 21 & & - \\
\hline 22 & & - \\
\hline
\end{tabular}

The N-terminal substitution peptides, with replacement of R17 with shorter, hydrophobic, and sulfur containing residues targeting the cysteine residues and hydrophobic patches near the entrance of the pocket, resulted in weaker binding affinity. For the C-terminus, L22 sits in a largely hydrophobic pocket with some charge on the periphery. Peptides with largely hydrophobic substitutions at L22 (beta-cyclohexylalanine (15), L-homoleucine (16), o-methyl-L-tyrosine (17), tert-butyl-Lcysteine (18), L-3-pyridylalanine (19)) tended to bind well, but only the beta-cyclohexylalanine (15) substitution peptide 
( $\left.K_{\mathrm{d}} \approx 0.12 \mu \mathrm{M}\right)$ matched the binding of the norleucine peptide (2) $\left(K_{\mathrm{d}} \approx 0.14 \mu \mathrm{M}\right)$. Isoleucine $(21)$ in this position perhaps provided some steric hindrance to binding. Introduction of more charge (o-acetyl-L-serine (20) and L-methionine sulfone (22)) in an attempt to interact with charged groups on the periphery of the pocket was not successful and weakened or eliminated binding.

The substitution of the unnatural amino acid norleucine for lysine 20 in the $\mathrm{H} 4$ (16-23) peptide has therefore provided a potent peptide. Further modification including additional residue substitutions in the $\mathrm{N}$ - or C-termini regions or truncation of the $\mathrm{N}$ - and $\mathrm{C}$-termini of the norleucine peptide did not improve potency. The norleucine substituted peptide (2) was then tested as a SETD8 substrate competitive inhibitor against the $\mathrm{H} 4$ peptide in the presence of SAM. It was found to have a $K_{\mathrm{i}}$ of $\sim 50 \mathrm{nM}$ (Supporting Information, Figure S4) and an $\mathrm{IC}_{50}$ of $0.33 \mu \mathrm{M}$ (Figure 3 ). It also showed good selectivity when tested against a panel of 32 methyltransferases ${ }^{25}$ (Figure 4).

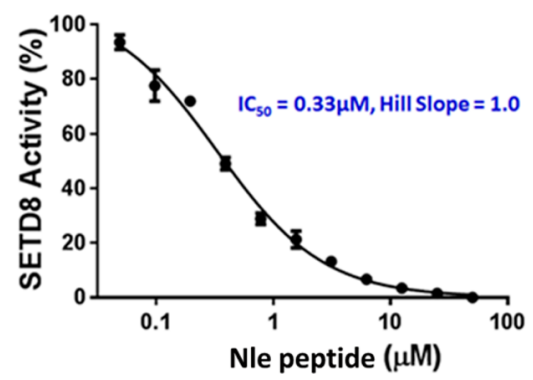

Figure 3. SETD8 activity with the norleucine substituted peptide (2), listed as Nle peptide in this figure, competing against the native $\mathrm{H} 4$ peptide (1-24). Experiments were performed in triplicate.

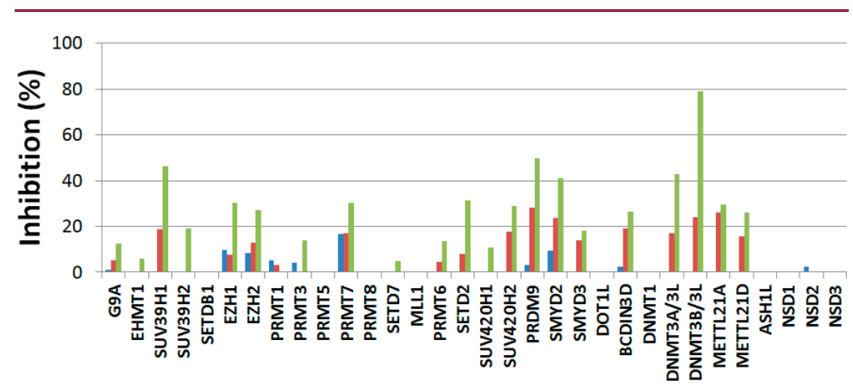

Figure 4. Selectivity of the norleucine substituted peptide (2) against a panel of 32 methyltransferases. Experiments performed in duplicate with average presented. Average estimated error $\pm 4 \%$ inhibition. Peptide concentration, blue $1 \mu \mathrm{M}$, red $10 \mu \mathrm{M}$, and green $30 \mu \mathrm{M}$.

Thus, we have discovered a potent and selective inhibitor of SETD8 and provided a soluble in vitro tool to further assess SETD8 function. For use as a therapeutic, the peptide would need to penetrate the cell membrane. While transfer across the cell membrane can be problematic for peptide therapeutics, this is an area of active research ${ }^{26,27}$ and a focus of further study for our laboratory.

\section{ASSOCIATED CONTENT}

\section{S Supporting Information}

The Supporting Information is available free of charge on the ACS Publications website at DOI: 10.1021/acsmedchemlett.6b00303.
Experimental methods for peptide synthesis, peptide screening by NMR, peptide binding by ITC, crystallization and structure determination, and enzymatic competition assay. Representative results and illustrations for ITC peptide binding, NMR ${ }^{13} \mathrm{C}$-HSQC spectra for peptide binding, SETD8 surface binding pockets for $\mathrm{H} 4$ peptide (16-23) residues R17 and L22, enzymatic competition data, X-ray diffraction and refinement statistics, peptide mass spectrometry, and analytical HPLC characterization (PDF)

\section{AUTHOR INFORMATION}

\section{Corresponding Author}

*E-mail: andrew.petros@abbvie.com.

\section{Present Address}

$\dagger$ (W.Y.) Harvard Medical School, Dana-Farber Cancer Institute, Boston, Massachusetts 02115, United States.

\section{Author Contributions}

The manuscript was written through contributions of all authors. All authors have given approval to the final version of the manuscript.

\section{Notes}

The authors declare the following competing financial interest(s): The Structural Genomics Consortium (authors W.Y., M.V., F.L., and P.J.B.) is a registered charity (number 1097737) that receives funds from AbbVie, Bayer Pharma AG, Boehringer Ingelheim, Canada Foundation for Innovation, Eshelman Institute for Innovation, Genome Canada, Innovative Medicines Initiative (EU/EFPIA), Janssen, Merck \& Co., Novartis Pharma AG, Pfizer, So Paulo Research FoundationFAPESP, Takeda, and Wellcome Trust. R.A.J., H.Z., A.K.U., P.M.B., C.W.H., M.T., V.L.M., W.N.P., C.S., and A.M.P. are employees of AbbVie. The design, study conduct, and financial support for the research of these authors were provided by AbbVie. AbbVie participated in the interpretation of the data, review, and approval of the publication.

\section{ACKNOWLEDGMENTS}

X-ray diffraction data were collected at beamline 17-ID in the facilities of the Industrial Macromolecular Crystallography Association Collaborative Access Team (IMCA-CAT) at the Advanced Photon Source. These facilities are supported by the companies of the Industrial Macromolecular Crystallography Association. Use of the Advanced Photon Source, an Office of Science User Facility operated for the U.S. Department of Energy (DOE) Office of Science by Argonne National Laboratory, was supported by the U.S. DOE under Contract No. DE-AC02-06CH11357.

\section{ABBREVIATIONS}

HMT, histone methyltransferase; SAM, S-adenosylmethionine; SAH, $S$-adenosylhomocysteine; ITC, isothermal titration calorimetry; Nle, norleucine

\section{REFERENCES}

(1) Beck, D. B.; Oda, H.; Shen, S. S.; Reinberg, D. PR-Set7 and H4K20me1: At the crossroads of genome integrity, cell cycle, chromosome condensation, and transcription. Genes Dev. 2012, 26, 325-337.

(2) Couture, J.-F.; Collazo, E.; Brunzelle, J. S.; Trievel, R. C. Structural and functional analysis of SET8, a histone H4 Lys-20 methyltransferase. Genes Dev. 2005, 19, 1455-1465. 
(3) Jorgensen, S.; Schotta, G.; Sorensen, C. S. Histone H4 Lysine 20 methylation: Key player in epigenetic regulation of genomic integrity. Nucleic Acids Res. 2013, 41, 2797-2806.

(4) Shi, X.; Kachirskaia, I.; Yamaguchi, H.; West, L. E.; Wen, H.; Wang, E. W.; Dutta, S.; Appella, E.; Gozani, O. Modulation of p53 function by SET8-mediated methylation at lysine 382. Mol. Cell 2007, 27, 636-646.

(5) Takawa, M.; Cho, H.-S.; Hayami, S.; Toyokawa, G.; Kogure, M.; Yamane, Y.; Iwai, Y.; Maejima, K.; Ueda, K.; Masuda, A.; Dohmae, N.; Field, H. I.; Tsunoda, T.; Kobayashi, T.; Akasu, T.; Sugiyama, M.; Ohnuma, S.-i.; Atomi, Y.; Ponder, B. A. J.; Nakamura, Y.; Hamamoto, R. Histone lysine methyltransferase SETD8 promotes carcinogenesis by deregulating PCNA expression. Cancer Res. 2012, 72, 3217-3227.

(6) Yang, F.; Sun, L.; Li, Q.; Han, X.; Lei, L.; Zhang, H.; Shang, Y. SET8 promotes epithelial-mesenchymal transitions and confers TWIST dual transcriptional activities. EMBO J. 2012, 31, 110-123.

(7) Yin, Y.; Liu, C.; Tsai, S. N.; Zhou, B.; Ngai, S. M.; Zhu, G. SET8 recognizes the sequence RHRK20VLRDN within the $\mathrm{N}$ terminus of histone H4 and mono-methylates lysine 20. J. Biol. Chem. 2005, 280, 30025-31.

(8) Williams, D. E.; Dalisay, D. S.; Li, F.; Amphlett, J.; Maneerat, W.; Chavez, M. A. G.; Wang, Y. A.; Matainaho, T.; Yu, W.; Brown, P. J.; Arrowsmith, C. H.; Vedadi, M.; Andersen, R. J. Nahuoic Acid A Produced by a Streptomyces sp. Isolated From a Marine Sediment Is a Selective SAM-Competitive Inhibitor of the Histone Methyltransferase SETD8. Org. Lett. 2013, 15, 414-417.

(9) Blum, G.; Ibanez, G.; Rao, X.; Shum, D.; Radu, C.; Djaballah, H.; Rice, J. C.; Luo, M. Small-molecule inhibitors of SetD8 with cellular activity. ACS Chem. Biol. 2014, 9, 2471-2478.

(10) Valente, S.; Lepore, I.; Dell'Aversana, C.; Tardugno, M.; Castellano, S.; Sbardella, G.; Tomassi, S.; Di Maro, S.; Novellino, E.; Di Santo, R.; Costi, R.; Altucci, L.; Mai, A. Identification of PR-SET7 and EZH2 selective inhibitors inducing cell death in human leukemia U937 cells. Biochimie 2012, 94, 2308-2313.

(11) Ma, A.; Yu, W.; Li, F.; Bleich, R. M.; Herold, J. M.; Butler, K. V.; Norris, J. L.; Korboukh, V.; Tripathy, A.; Janzen, W. P.; Arrowsmith, C. H.; Frye, S. V.; Vedadi, M.; Brown, P. J.; Jin, J. Discovery of a selective, substrate-competitive inhibitor of the lysine methyltransferase SETD8. J. Med. Chem. 2014, 57, 6822-6833.

(12) Ma, A.; Yu, W.; Xiong, Y.; Butler, K. V.; Brown, P. J.; Jin, J. Structure-activity relationship studies of SETD8 inhibitors. MedChemComm 2014, 5, 1892-1898.

(13) Yu, W.; Tempel, W.; Li, Y.; El Bakkouri, M.; Shapira, M.; Bountra, C.; Arrowsmith, C. H.; Edwards, A. M.; Brown, P. J. Crystal structure of the complex of SETD8 with SAM. PDB code 4IJ8.

(14) McCabe, M. T.; Ott, H. M.; Ganji, G.; Korenchuk, S.; Thompson, C.; Van Aller, G. S.; Liu, Y.; Graves, A. P.; Della Pietra, A., III; Diaz, E.; LaFrance, L. V.; Mellinger, M.; Duquenne, C.; Tian, X.; Kruger, R. G.; McHugh, C. F.; Brandt, M.; Miller, W. H.; Dhanak, D.; Verma, S. K.; Tummino, P. J.; Creasy, C. L. EZH2 inhibition as a therapeutic strategy for lymphoma with EZH2-activating mutations. Nature 2012, 492, 108-112.

(15) Yu, W.; Chory, E. J.; Wernimont, A. K.; Tempel, W.; Scopton, A.; Federation, A.; Marineau, J. J.; Qi, J.; Barsyte-Lovejoy, D.; Yi, J.; Marcellus, R; Iacob, R. E.; Engen, J. R.; Griffin, C.; Aman, A.; Wienholds, E.; Li, F.; Pineda, J.; Estiu, G.; Shatseva, T.; Hajian, T.; Alawar, R.; Dick, J. E.; Vedadi, M.; Brown, P. J.; Arrowsmith, C. H.; Bradner, J. E.; Schapira, M. Catalytic site remodelling of the DOT1L methyltransferase by selective inhibitors. Nat. Commun. 2012, 3, 1288.

(16) Sweis, R. F.; Pliushchev, M.; Brown, P. J.; Guo, J.; Li, F.; Maag, D.; Petros, A. M.; Soni, N. B.; Tse, C.; Vedadi, M.; Michaelides, M. R.; Chiang, G. G.; Pappano, W. N. Discovery and development of potent and selective inhibitors of histone methyltransferase G9a. ACS Med. Chem. Lett. 2014, 5, 205-209.

(17) Sweis, R. F.; Wang, Z.; Algire, M.; Arrowsmith, C. H.; Brown, P. J.; Chiang, G. G.; Guo, J.; Jakob, C. G.; Kennedy, S.; Li, F.; Maag, D.; Shaw, B.; Soni, N. B.; Vedadi, M.; Pappano, W. N. Discovery of A-893, a new cell-active benzoxazinone inhibitor of lysine methyltransferase SMYD2. ACS Med. Chem. Lett. 2015, 6, 695-700.
(18) Flygare, J. A.; Beresini, M.; Budha, N.; Chan, H.; Chan, I. T.; Cheeti, S.; Cohen, F.; Deshayes, K.; Doerner, K.; Eckhardt, S. G.; Elliott, L. O.; Feng, B.; Franklin, M. C.; Reisner, S. F.; Gazzard, L.; Halladay, J.; Hymowitz, S. G.; La, H.; LoRusso, P.; Maurer, B.; Murray, L.; Plise, E.; Quan, C.; Stephan, J.-P.; Young, S. G.; Tom, J.; Tsui, V.; Um, J.; Varfolomeev, E.; Vucic, D.; Wagner, A. J.; Wallweber, H. J. A.; Wang, L.; Ware, J.; Wen, Z.; Wong, H.; Wong, J. M.; Wong, M.; Wong, S.; Yu, R.; Zobel, K.; Fairbrother, W. J. Discovery of a Potent Small-Molecule Antagonist of Inhibitor of Apoptosis (IAP) Proteins and Clinical Candidate for the Treatment of Cancer (GDC-0152). J. Med. Chem. 2012, 55, 4101-4113.

(19) Hom, R. K.; Fang, L. Y.; Mamo, S.; Tung, J. S.; Guinn, A. C.; Walker, D. E.; Davis, D. L.; Gailunas, A. F.; Thorsett, E. D.; Sinha, S.; Knops, J. E.; Jewett, N. E.; Anderson, J. P.; John, V. Design and Synthesis of Statine-Based Cell-Permeable Peptidomimetic Inhibitors of Human beta-Secretase. J. Med. Chem. 2003, 46, 1799-1802.

(20) Glas, A.; Bier, D.; Hahne, G.; Rademacher, C.; Ottmann, C.; Grossmann, T. N. Constrained peptides with target-adapted crosslinks as inhibitors of a pathogenic protein-protein interaction. Angew. Chem., Int. Ed. 2014, 53, 2489-2493.

(21) LaBelle, J. L.; Katz, S. G.; Bird, G. H.; Gavathiotis, E.; Stewart, M. L.; Lawrence, C.; Fisher, J. K.; Godes, M.; Pitter, K.; Kung, A. L.; Walensky, L. D. A stapled BIM peptide overcomes apoptotic resistance in hematologic cancers. J. Clin. Invest. 2012, 122, 2018-2031.

(22) Liu, S.; Desharnais, J.; Sahasrabudhe, P. V.; Jin, P.; Li, W.; Oates, B. D.; Shanker, S.; Banker, M. E.; Chrunyk, B. A.; Song, X.; Feng, X.; Griffor, M.; Jimenez, J.; Chen, G.; Tumelty, D.; Bhat, A.; Bradshaw, C. W.; Woodnutt, G.; Lappe, R. W.; Thorarensen, A.; Qiu, X.; Withka, J. M.; Wood, L. D. Inhibiting complex IL-17A and IL-17RA interactions with a linear peptide. Sci. Rep. 2016, 6, 26071.

(23) The PyMOL Molecular Graphics System, version 1.7.6.6 Schrodinger, LLC: New York.

(24) Schrodinger. Maestro, version 9.7; Schrodinger, LLC: New York, 2014; Schrodinger Release 2014-1.

(25) Shen, Y.; Szewczyk, M. M.; Eram, M. S.; Smil, D.; Kaniskan, H. U.; Ferreira de Freitas, R.; Senisterra, G.; Li, F.; Schapira, M.; Brown, P. J.; Arrowsmith, C. H.; Barsyte-Lovejoy, D.; Liu, J.; Vedadi, M.; Jin, J. Discovery of a potent, selective, and cell-active dual inhibitor of protein arginine methyltransferase 4 and protein arginine methyltransferase 6. J. Med. Chem. 2016, DOI: 10.1021/acs.jmedchem.6b01033.

(26) Appelbaum, J. S.; LaRochelle, J. R.; Smith, B. A.; Balkin, D. M.; Holub, J. M.; Schepartz, A. Arginine topology controls escape of minimally cationic proteins from early endosomes to the cytoplasm. Chem. Biol. 2012, 19, 819-830.

(27) Marks, J. R.; Placone, J.; Hristova, K.; Wimley, W. C. Spontaneous membrane-translocating peptides by orthogonal highthroughput screening. J. Am. Chem. Soc. 2011, 133, 8995-9004. 